\title{
Resistance is futile: RNA-sequencing reveals differing responses to bat fungal pathogen in Nearctic Myotis lucifugus and Palearctic Myotis myotis
}

\author{
Thomas M. Lilley ${ }^{1,2}$ (D) Jenni M. Prokkola ${ }^{2}$ - Anna S. Blomberg ${ }^{3} \cdot$ Steve Paterson ${ }^{2} \cdot$ Joseph S. Johnson ${ }^{4}$. \\ Gregory G. Turner ${ }^{5} \cdot$ Tomáš Bartonička $^{6} \cdot$ Erik Bachorec $^{6} \cdot$ DeeAnn M. Reeder $^{7} \cdot$ Kenneth A. Field $^{7}$
}

Received: 7 August 2019 / Accepted: 30 August 2019 / Published online: 10 September 2019

(c) The Author(s) 2019

\begin{abstract}
Resistance and tolerance allow organisms to cope with potentially life-threatening pathogens. Recently introduced pathogens initially induce resistance responses, but natural selection favors the development of tolerance, allowing for a commensal relationship to evolve. Mycosis by Pseudogymnoascus destructans, causing white-nose syndrome (WNS) in Nearctic hibernating bats, has resulted in population declines since 2006. The pathogen, which spread from Europe, has infected species of Palearctic Myotis for a longer period. We compared ecologically relevant responses to the fungal infection in the susceptible Nearctic M. lucifugus and less susceptible Palearctic M. myotis, to uncover factors contributing to survival differences in the two species. Samples were collected from euthermic bats during arousal from hibernation, a naturally occurring phenomenon, during which transcriptional responses are activated. We compared the whole-transcriptome responses in wild bats infected with $P$. destructans hibernating in their natural habitat. Our results show dramatically different local transcriptional responses to the pathogen between uninfected and infected samples from the two species. Whereas we found 1526 significantly upregulated or downregulated transcripts in infected $M$. lucifugus, only one transcript was downregulated in $M$. myotis. The upregulated response pathways in M. lucifugus include immune cell activation and migration, and inflammatory pathways, indicative of an unsuccessful attempt to resist the infection. In contrast, M. myotis appears to tolerate $P$. destructans infection by not activating a transcriptional response. These host-microbe interactions determine pathology, contributing to WNS susceptibility, or commensalism, promoting tolerance to fungal colonization during hibernation that favors survival.
\end{abstract}

Communicated by Indrikis Krams.

Electronic supplementary material The online version of this article (https://doi.org/10.1007/s00442-019-04499-6) contains supplementary material, which is available to authorized users.

Thomas M. Lilley

thomas.lilley@helsinki.fi

1 Finnish Museum of Natural History, University of Helsinki, Helsinki, Finland

2 Institute of Integrative Biology, University of Liverpool, Liverpool, UK

3 Department of Biology, University of Turku, Turku, Finland

4 Department of Biological Sciences, Ohio University, Athens, $\mathrm{OH}, \mathrm{USA}$

5 Pennsylvania Game Commission, Harrisburg, PA, USA

6 Department of Botany and Zoology, Masaryk University, Brno, Czech Republic

7 Biology Department, Bucknell University, Lewisburg, PA, USA 


\section{Graphic abstract}

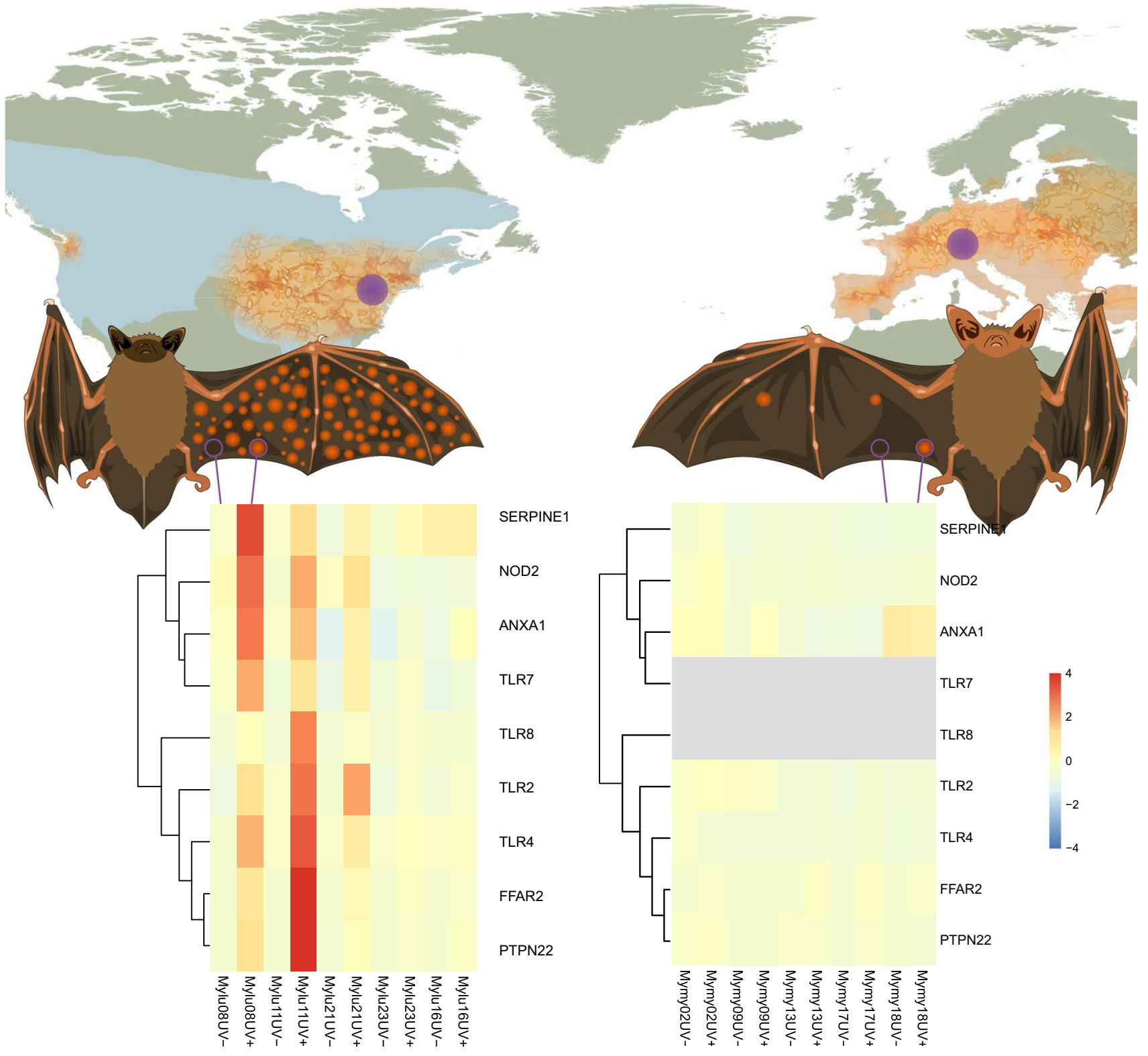

Keywords Host-pathogen interaction $\cdot$ Resistance $\cdot$ Tolerance $\cdot$ Infection $\cdot$ Opportunistic pathogen

\section{Introduction}

Exposure to novel pathogens in naive wildlife populations has increased over the last decades (Daszak et al. 2000). Many of these introductions are caused by humans inadvertently transporting microbes with pathogenic potential to new geographic locations, where they emerge as a major concern for native species (Tompkins et al. 2015). That is, the disease often occurs when there is a host shift or a change in host ecology, or in environmental conditions (Scholthof 2007). With chytridiomycosis, the worldwide fungal amphibian epidemic, disease was related to the emergence of a hypervirulent strain of fungus (Eskew and Todd 2013). In contrast, white-nose syndrome (WNS), a bat fungal disease, has been linked to varied host responses rather than increased pathogen virulence (Field et al. 2015; Leopardi et al. 2015; 
Bandouchova et al. 2018). WNS is caused by Pseudogymnoascus destructans, and has resulted in extensive declines in populations of several bat species since arriving in North America likely from Eurasia in 2006 (Blehert et al. 2009; Frick et al. 2010; Leopardi et al. 2015; Campana et al. 2017).

The psychrophilic fungus, $P$. destructans infects insectivorous bat hosts during hibernation. In Nearctic bats, the associated pathology leads to increased arousal frequency, consuming valuable energy reserves (Warnecke et al. 2012; Reeder et al. 2012). The detrimental effects of infection by $P$. destructans vary geographically and between hosts (Zukal et al. 2014, 2016; Bernard et al. 2015; Lilley et al. 2018; Bandouchova et al. 2018); bats in the genus Myotis, such as $M$. lucifugus and $M$. septentrionalis, appear to be especially susceptible. In M. lucifugus, mechanisms leading to pathology are expressed through a cascade of physiological responses (Verant et al. 2014; Field et al. 2015, 2018) and the immune response to the fungal infection is not able to provide protection (Johnson et al. 2015; Lilley et al. 2017). Pseudogymnoascus destructans is endemic in European bat hibernacula (Wibbelt et al. 2010; Martinkova et al. 2010; Puechmaille et al. 2011), where the fungus and cupping erosions in wing tissue of hosts, a diagnostic feature of infection by $P$. destructans, are found in at least 13 countries (Meteyer et al. 2009), in at least 15 species of bats (Zukal et al. 2016). Similar to North America, in Europe it appears that species in the genus Myotis are the most likely hosts, exhibiting similar tissue damage to Nearctic species (Zukal et al. 2016). However, despite the presence of P. destructans in the environment, and even invasion of host tissue, i.e. pathology, there are no signs of mass mortality in contemporary Palearctic bat populations (Wibbelt et al. 2010; Martinkova et al. 2010; Puechmaille et al. 2011; Pikula et al. 2012; Bandouchova et al. 2015). In fact, populations of bats preferentially hibernating at underground sites appear to be increasing (Van der Meij et al. 2015). However, mass accumulations of skeletal remains of Myotis bats in European cave deposits dating to the Pliocene and Pleistocene (c. 1.8-3.6 MYA) suggest a mass mortality event in the past (Martinkova et al. 2010). These mass accumulations may have been related to die-offs associated with WNS suggesting the Palearctic clade of Myotis would have gone through a selective event and have since coexisted with the pathogen (Harazim et al. 2018). The Palearctic and Nearctic Myotis clades diverged millions of years prior to this hypothesized event, approximately 12.2 MYA, consistent with North American bats remaining unexposed to the pathogen until recently (Ruedi et al. 2013).

Palearctic strains of $P$. destructans are able to infect Nearctic bats (Warnecke et al. 2012). Although strains on both continents show significant genetic similarity (Leopardi et al. 2015), Palearctic bats exposed to the North American strain appear to not get infected under captive conditions
(Davy et al. 2017; Field et al. 2018a, b). It is unlikely that the high mortality caused by WNS in Nearctic bats is caused by a hypervirulent strain, such as in chytrid mycosis (Eskew and Todd 2013). Rather, it is differences in host susceptibility that appear to explain the different outcomes between Palearctic and Nearctic species (Bandouchova et al. 2018), which is supported by the overwintering success of Palearctic bats under similar pathogen pressure as their infected Nearctic counterparts (Zukal et al. 2016).

Palearctic bats, such as Myotis myotis, have been shown to tolerate infection by $P$. destructans (Bandouchova et al. 2018; Zukal et al. 2016). In contrast to resistance, which protects the host by actively reducing the pathogen burden, tolerance limits the harm caused by the pathogen, but has a neutral or even positive effect on the prevalence of the pathogen in the host population, as witnessed in Palearctic bat populations expressing high fungal loads, almost $100 \%$ prevalence, and only moderate pathology (Råberg et al. 2009; Martinkova et al. 2010; Zukal et al. 2014, 2016). Palearctic species of Myotis may have coevolved with P. destructans and the fungus may now exhibit a commensal or parasitic relationship with these less susceptible species.

Hibernating $M$. lucifugus severely infected with $P$. destructans show large, local transcriptional responses in genes associated with immune function during the intermittent euthermic bouts occurring throughout hibernation, whereas the local transcriptional response to infection is very low during torpor Field et al. (2018). The inflammatory responses, occurring only during arousals Field et al. (2018), maybe maladaptive, and the immunopathology related to infection could be a major driver of mortality associated with WNS, at least in M. lucifugus (Lilley et al. 2017). Recent reports have described populations of M. lucifugus in northeastern North America that are beginning to stabilize at substantially reduced population sizes, or even showing signs of population increase since the initial mass mortality following the arrival of WNS (Langwig et al. 2017; Dobony and Johnson 2018). This has led to speculation that this could be due to strong selection for those individual bats that responded to $P$. destructans with tolerance rather than a detrimental overresponse to fungal infection (Frick et al. 2017). Indeed, the balance between commensalism and pathogenesis is critical in many fungal diseases (Iliev and Underhill 2013). Interestingly, these remnant populations show high pathogen loads and signs of host tissue invasion, but no associated increase in arousal frequency, which is suggestive of tolerance (Lilley et al. 2016). There is, therefore, an important need to study the mechanisms of host survival in both Palearctic and survivor populations of Nearctic bats, as comparing host responses in these regions may provide clues to how Nearctic bats might be able to adapt to the pathogen, and what responses may result in continued mortality in Nearctic populations. 
Here, we take a whole-transcriptome approach to compare responses of wild individuals of two species of Myotis commonly infected with $P$. destructans during the hibernation period: the Palearctic $M$. myotis, with a lengthy coexistence with the pathogen, and the Nearctic M. lucifugus from a remnant survivor population in Pennsylvania, United States, exposed to $P$. destructans c. 2009. Although a common garden approach should ideally be favored, we adopted to use wild animals in their natural habitat, because infection of captive $M$. myotis is difficult (Field et al. 2018a, b) and may lead to unrelated infections (Moore et al. 2018; Abbott et al. 2019). A previous study that attempted to address this question (Davy et al. 2017) was unable to measure any response to infection in captive $M$. myotis because the samples did not contain detectable levels of $P$. destructans (Davy et al. 2017). Therefore, we used non-lethal samples collected from bats hibernating in their natural habitat, and thus showing ecologically relevant responses to the fungal infection during their intermittent arousals, to determine how transcriptional responses to confirmed $P$. destructans infection differed in the two studied species. A sample from a location with fungal growth and another from a location with no growth was collected from euthermic bats during arousal from hibernation (Field et al. 2018). We predict that euthermic transcriptional responses in wing tissue during the hibernation period will reflect the differences in past exposure to the pathogen between the two species. In addition, we compare the results to a similar, previous study conducted on naïve $M$. lucifugus in their first year of coming into contact with the pathogen (Field et al. 2018). Tolerance to $P$. destructans is predicted to produce transcriptomic responses that either differs little between infected (UV-positive) and control (UV-negative) samples or show upregulationof anti-inflammatory and tissue repair pathways in infected tissue compared to control tissue (Soares et al. 2017; Medzhitov et al. 2012).

\section{Methods}

\section{Ethical statement}

Animals in the U.S. were collected and studied with Pennsylvania Game Commission Special Use Permit 33085. Sample collection protocols were approved by Bucknell University Institutional Animal Care and Use Committee (IACUC\# DMR-16) in accordance with guidelines set forth by the USDA and PHS Policy on Humane Care and Use of Laboratory Animals under the guidance of the Office of Laboratory Animal Welfare (OLAW). The institution has an Animal Welfare Assurance on file with the NIH Office for the Protection of Research Risks (OPRR), Number A3525-01. Fieldwork and bat sampling in the Czech Republic were performed in accordance with Czech Law
No. 114/1992 on Nature and Landscape Protection, based on permits 1662/MK/2012S/00775/MK/2012, 866/JS/2012 and $00356 / \mathrm{KK} / 2008 / \mathrm{AOPK}$ issued by the Agency for Nature Conservation and Landscape Protection of the Czech Republic. Experimental procedures were approved by the Ethical Committee of the Czech Academy of Sciences (No. 16256/2015-MZE-17214). The author of the present study (TB) was authorized to handle free-living bats in agreement with Czech Certificate of Competency No. CZ01297 (\$17, Act No. 246/1992).

\section{Sample collection}

To compare the response of hosts to infection, we collected wing tissue samples from bats infected with $P$. destructans. For each bat, a pair of samples were collected: one sample was from a region of the wing with evidence of fungal growth and a second sample was from a region of the wing without evidence of fungal growth. These paired samples were obtained from adult wild male $M$. lucifugus $(N=5)$ and M. myotis $(N=5)$ during the last quartile of the hibernation period (18 Mar 2018 and 20 Mar 2018, respectively). The M. lucifugus samples were collected from a hibernaculum in Woodward, Pennsylvania, where population numbers have begun to increase in the past few years after initially declining by $90 \%$ due to WNS (GR Turner, pers. comment). The M. myotis samples were collected from the Simon a Juda mine, Czech Republic, with temporally stable population sizes. At both sites, torpid bats were collected from the walls, and their wings were immediately UV-transilluminated and photographed (Turner et al. 2014). A single fluorescing area (UV-positive), indicating infection of host tissue by $P$. destructans, was circled on the right wing using a sharpie and a non-fluorescent (UV-negative), control area was circled on the left wing (Fig. S1). Although P. destructans causes a local immune response (vs. systemic, Field et al. 2015) at infected sites, we prefer to use UV-positive and UVnegative to describe to distinguish the sample types, seeing as ultimately pathology occurs at the individual level. The bats were allowed to arouse from torpor for 60-120 $\mathrm{min}$ to initiate responses (Lilley et al. 2017; Field et al. 2018). After arousal, the circled areas were sampled using $5 \mathrm{~mm}$ biopsy punches (MLT3335, Miltex Instrument Co, Plainsboro, New Jersey) and placed in RNAlater (ThermoFischer, Waltham, Massachusetts). After this, the bats were sexed, the forearms were measured and their mass was recorded. The bats were released after the procedures. The samples were left at ambient temperature for $6-8 \mathrm{~h}$ to allow permeation of RNAlater into the tissue, after which the samples were transferred to $\mathrm{a}-80{ }^{\circ} \mathrm{C}$ freezer for storage. 


\section{Quantifying WNS-lesions}

To quantify the severity of fungal infection, we transilluminated the wing membranes of each bat using a UV lamp emitting light at a wavelength of $368 \mathrm{~nm}$ (Turner et al. 2014). Each wing was photographed while transilluminated, and the number of fluorescent spots on each wing was calculated from the photographs (Figure S1). According to (Pikula et al. 2017), the number of UV-fluorescent lesions correlates with WNS pathology, demonstrating congruence between WNS-associated tissue damage and the extent of UV fluorescence. The number of lesions, calculated from photographs at the time of sampling, were considerably lower in M. myotis compared to M. lucifugus (Table S1).

\section{RNA extraction and sequencing}

To avoid batch effects arising from RNA extractions, samples from the two species were extracted in mixed batches, with both wing punches from the same individual extracted in the same batch. RNA was extracted with Qiagen RNeasy Micro kit (Qiagen, Hilden, Germany), including a DNase I treatment. Samples were homogenized using motorized plastic pestles in $300 \mu \mathrm{L}$ buffer RLT with $\beta$-mercaptoethanol, after which the manufacturer's protocol was followed. RNA was eluted in nuclease-free water and stored at $-80^{\circ} \mathrm{C}$. Samples were checked for quality using the Pico chip in Bioanalyzer 2100 (Agilent Technologies, Santa Clara, California). RNA Integrity values ranged from 5.7 to 8.9 and were on average 6.7 and 8.3 for M. lucifugus and M. myotis, respectively. RNA sequencing was performed by the University of Liverpool Centre for Genomic Research. Poly A-tailed RNA was enriched from total RNA samples using two rounds of selection with NEBNext Poly(A) mRNA Magnetic Isolation Module and assessed by Bioanalyser. RNA-Seq libraries were prepared from the Poly A selected material using the NEBNext Ultra Directional RNA Library Prep Kit for Illumina. Each library was quantified using Qubit and the size distribution assessed using the Bioanalyzer. These final libraries were pooled in equimolar amounts using the Qubit and Bioanalyzer data. The quantity and quality of each pool were assessed by Bioanalyzer and subsequently by qPCR using the Illumina Library Quantification Kit from Kapa (KK4854) on a Roche Light Cycler LC480II according to manufacturer's instructions. The libraries were sequenced across two lanes of the HiSeq 4000 at $2 \times 100$ bp paired-end sequencing and produced an average of 29 million reads per sample. The raw FASTQ files were trimmed for the presence of Illumina adapter sequences using Cutadapt version 1.2.1. (Martin 2011). The reads were further trimmed using Sickle version 1.200 (Joshi and Fass 2011) with a minimum window quality score of 20.

\section{Gene expression}

Prior to analysis of host gene expression, transcript levels of $P$. destructans were determined by alignment of trimmed reads to the concatenated genomes of $M$. lucifugus (Myoluc2.0, Ensembl release 84 (Yates et al. 2015) and $P$. destructans (Drees et al. 2016) with STAR v.2.6.1a (Dobin et al. 2013) and counts estimated with RSEM v1.3.1 (Li and Dewey 2011). Quantification of P. destructans transcript expression in transcripts per million (TPM) was used to determine the level of infection in each sample. The $P$. destructans transcripts were then removed from further analysis. Mapping rates to M. lucifugus were higher for the samples from M. lucifugus $(85.7 \% \pm 0.6 \%)$ than for $M$. myotis $(76.9 \% \pm 0.8 \%$ ) (Table S2). Sample quality control and differential gene expression were then assessed using SARTools v.1.6.6 (Varet et al. 2016) and edgeR v.3.22.3 (Robinson et al. 2010). We used the scottyEstimate function of Scotty (Busby et al. 2013) to measure the statistical power of the differential expression study design with the following parameters: $\mathrm{fc}=2$, pCut $=0.05$, minPercDetected $=50$, cost PerRepControl $=140$, costPerRepTest $=140$, costPerMillionReads $=10$, totalBudget $=10,000$, maxReps $=10$, minReadsPerRep $=10,000,000$, maxReadsPerRep $=100,000,000$, minPercUnbiasedGenes $=50$, pwrBiasCutoff $=50$, and alignmentRate $=75$. Scotty analysis was performed in Matlab R2018a (9.4.0.813654).

Prior to differential expression testing, transcripts were filtered with a cutoff after TMM-normalization of 1 TPM in at least 5 samples. A generalized linear model was used to fit the TMM-normalized transcript counts using the individual as a batch effect ( individual + infection). Interactive MA plots were generated using Glimma v.1.10.1 (Su et al. 2017). Similar results were obtained using DESeq 2 v.1.20.0 (Love et al. 2014, p. 2) (Figure S2).

For M. lucifugus, gene ontology annotations were from Ensembl release 94 (Yates et al. 2015) and gene ontology enrichment analysis was performed using g:Profiler (Reimand et al. 2016) g:GOSt v.e94_eg41_p11_50c103b with a g:SCS threshold of 0.05. Enrichment was measured using ranked lists (by FDR) against the background of all annotated M. lucifugus genes. REVIGO (Supek et al. 2011) was used to filter the gene ontology categories for redundancy.

For calculating alignment rates to other genomes, STAR v.2.6.1 in quant mode was used to align reads to either $M$. davidii genome RefSeq assembly GCF_000327345.1 or $M$. brandtii RefSeq assembly GCF_000412655.1 (NCBI). For comparisons between the dataset generated in this study and our previous study of captive M. lucifugus $(n=6)$ from Wisconsin Field et al. (2018), we used the comBat function in the sva package v.3.28.0 (Johnson et al. 2007). This dataset is available as PRJNA393517 at the NCBI Sequence Read Archive. Paired samples of UV-negative and UV-positive 
biopsies were collected from $M$. lucifugus infected with $P$. destructans in captivity and sampled 70-80 min after emergence from torpor.

\section{Results}

This study set out to test the hypothesis that $M$. myotis exhibits similar whole-transcriptome responses to $P$. destructans infection as the M. lucifugus from remnant populations that are more recently exposed to the pathogen. We predicted that differences between the host transcriptomic responses between these two species would illuminate the mechanism for the reduced susceptibility of M. myotis to WNS. To verify that the M. myotis samples that we had obtained were infected with $P$. destructans, we first tested the strict a priori assumption that $P$. destructans transcript levels would be present at relative levels at least as high in M. myotis samples as in M. lucifugus samples.

To compare the local whole-transcriptomic responses of $M$. lucifugus and M. myotis to P. destructans infection, we obtained paired wing-tissue biopsies from bats of both species. Although the total number of lesions was lower in $M$. myotis (Table S1), we verified that an approximately equal amount of $P$. destructans was present in each group of biopsy samples by mapping of RNA-Seq reads (Fig. 1a). We found that UV-positive M. lucifugus contained 1475 \pm 1010 $P$. destructans transcripts per million mapped reads (TPM) and UV-positive M. myotis $3817 \pm 1965$ TPM (Welch twosample $t$ test, $\mathrm{p}=0.0557)$. The UV-negative samples from both species contained significantly less $P$. destructans than the UV-positive samples $(278 \pm 273$, paired t-test $\mathrm{p}=0.028$ for M. lucifugus, $\mathrm{p}=0.0044$ for $M$. myotis). The numbers of reads that mapped to $P$. destructans in the UV-negative samples was comparable to tissue samples from bats that have never been exposed to $P$. destructans Field et al. (2018a, b) and may represent other fungi with homologous transcripts. The relative levels of $P$. destructans reads in the UV-positive samples were lower than we have found in a previous study of M. lucifugus infected in captivity Field et al. (2018) and this precluded analysis of differential gene expression in $P$. destructans genes.

After removing reads that mapped to $P$. destructans, we compared host gene expression patterns for M. lucifugus and M. myotis. Principal component analysis showed that the two species were distinct in their gene expression patterns (Fig. 1b). We also found that the UV positive and UV negative M. lucifugus samples showed distinct patterns of gene expression, as expected, but this clustering was not observed for the M. myotis samples.

For M. lucifugus, the local changes in gene expression due to infection with P. destructans (Fig. 2a, Table 1) were similar in magnitude to what we observed in prior studies of this species Field et al. (2018). However, M. myotis showed much lower fold changes in gene expression due to local infection with $P$. destructans, despite similar levels of infection within the biopsied samples (Fig. 2b). Only one transcript was differentially expressed in $M$. myotis using the a priori FDR cutoff of 0.05 , while 1526 transcripts were differentially expressed in the M. lucifugus samples (Fig. 2c, Supplemental dataset 1). Similar results were obtained if DESeq 2 was used instead of edgeR or if transcripts were mapped to M. davidii $(72.2 \%+-0.8 \%$ for $M$. lucifugus samples and $75.0 \%+-0.6 \%$ for M. myotis samples) or

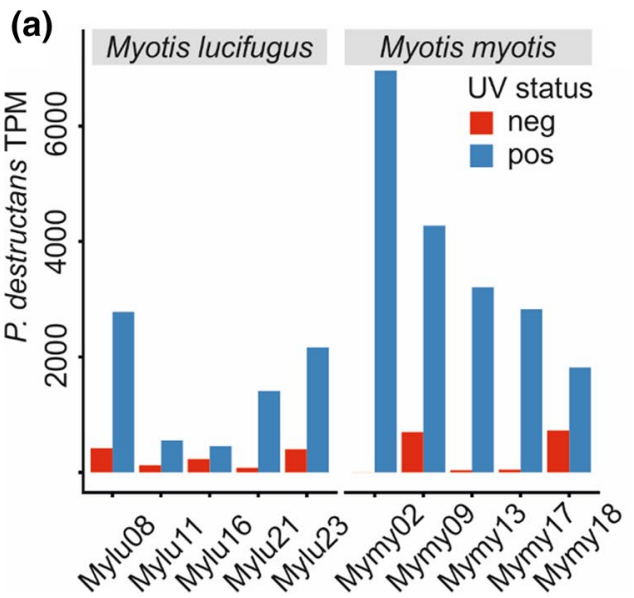

Fig. 1 a Loads of $P$. destructans in each sample determined by read mapping, b Principal component analysis of host transcript expression after removal of $P$. destructans reads. The load of $P$. destructans in each biopsy was determined by estimating $P$. destructans transcript counts in transcripts per million mapped reads (TPM). The multidi-

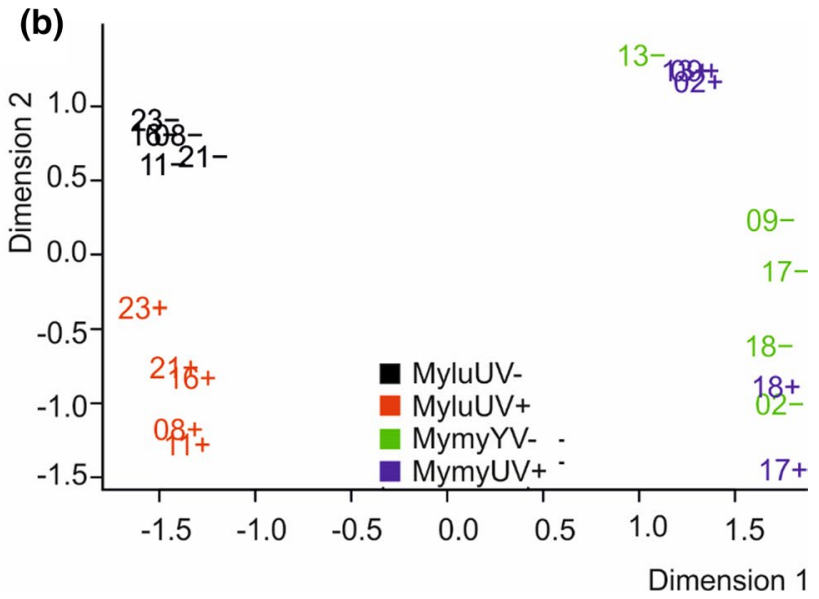

mensional scaling plot shows pairwise comparisons of $M$. lucifugus transcript expression using moderated log CPM expression levels. Samples are colored by group, as indicated on the legend. Dimension 1 represents $49 \%$ of the variance dimension 2 represents $25 \%$ of the variance 
Fig. 2 Differential expression of transcripts in tissues infected with $P$. destructans in a M. lucifugus, $\mathbf{b}$ in $M$. myotis and $\mathbf{c}$ a comparison of expression in both host species. The mean expression level $\left(\log _{2}\right.$ counts per million (CPM)) and the fold change $\left(\log _{2} \mathrm{FC}\right)$ are shown for each transcript. Red points indicate differential expression (FDR $\leq 0.05$ determined by edgeR). An interactive version of $\mathbf{a}$ is available at https://digitalcommons.bucknell.edu/fac_pubs/133/ and b at https://digitalcommons.bucknell.edu/fac_pubs/134/. The Venn diagram indicates the overlapping subsets of significantly differentially expressed transcripts (FDR $<0.05)$ in $M$. lucifugus (Mylu) and $M$. myotis (Mymy) samples

M. brandtii $(80.9 \%+-0.8 \%$ for M. lucifugus samples and $75.5 \%+-0.5 \%$ for $M$. myotis samples) transcriptomes instead of M. lucifugus (Figures S3B and S3C). The lack of differential expression in M. myotis was not due to low levels of mapping to the M. lucifugus transcriptome. Of the 1526 transcripts differentially expressed in M. lucifugus, 1396 (91.5\%) were expressed sufficiently in M. myotis to pass the expression cutoff. Using Scotty (Busby et al. 2013), we determined that the study design, with 5 replicates per group, was sufficiently statistically powerful to detect at least $50 \%$ of expressed genes that are differentially expressed by a $2 \mathrm{X}$ fold change at $p<0.05$ (Figure S4). Together, these results indicate that our study was sufficiently powerful to detect differential gene expression in M. myotis if it had been present.

We next used gene ontology analysis to determine the functional categories that were enriched in the transcripts that showed differential expression due to local infection of the M. lucifugus samples. We found that many of the differentially expressed genes were involved in muscle cell development/function and immune responses (Supplemental dataset 2). Many of the most enriched categories involved the development and function of muscle cells (for example, GO:0055002, striated muscle cell development, adjusted $p=5.9410^{-15}$ ), even after filtering for redundancy (Supplemental dataset S3). However, during exploratory data analysis we determined that the differential expression of these categories of muscle genes was due to the inadvertent bias of sampling biopsies from the plagiopatagium (wing tissue between the hindleg and the phalanges) or chiropatagium (wing tissue between the hindlegs and the tail). None of the M. myotis samples were obtained from the chiropatagium, while three $M$. lucifugus biopsies were from the chiropatagium, all in the UV negative group (Table S3). When we analyzed the M. lucifugus samples for differential expression based on biopsy location post hoc (Supplemental dataset 4), we found strong enrichment of muscle development and function gene ontology categories (for example, GO:0,055,002, striated muscle cell development, adjusted $p=1.07 \times 10^{-19}$ ).

The functional categories of genes enriched due to $P$. destructans infection in M. lucifugus included leukocyte

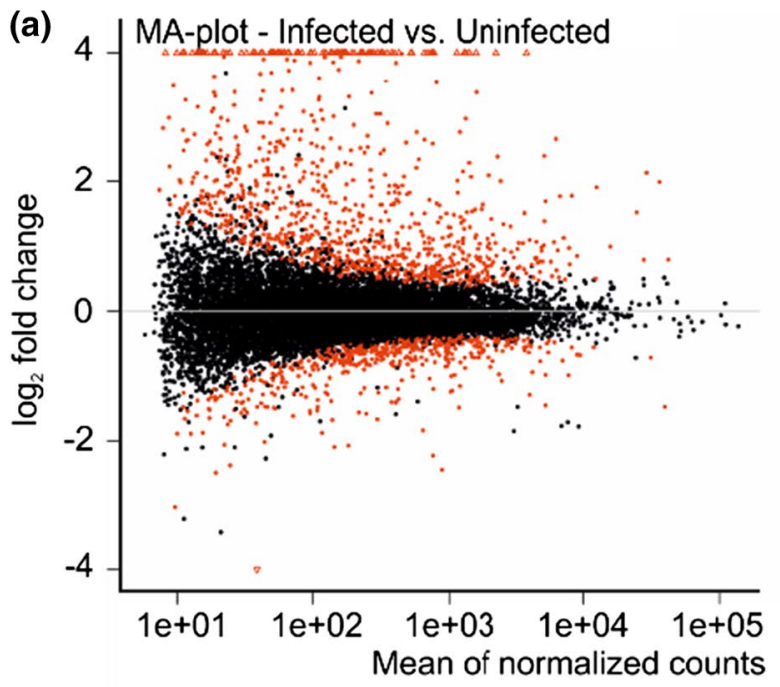

(b)

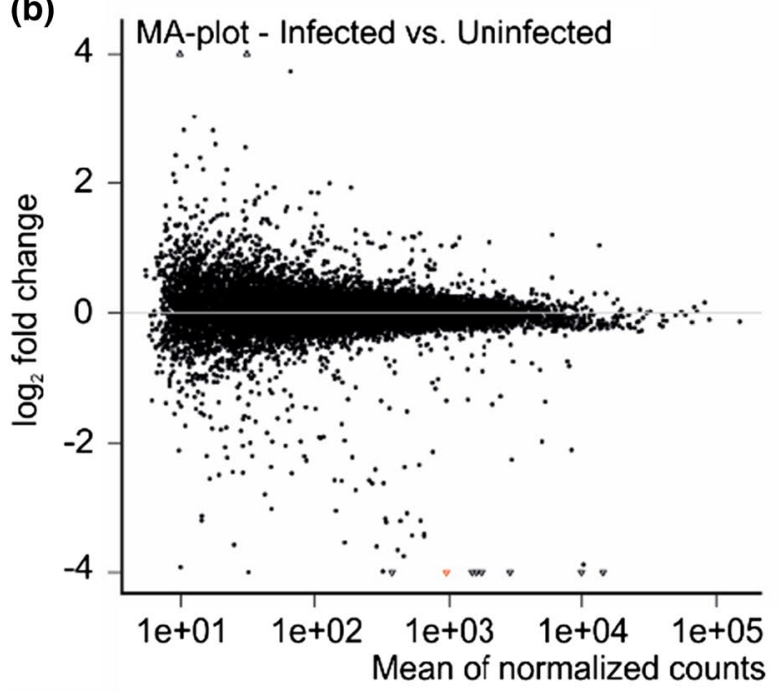

(c)

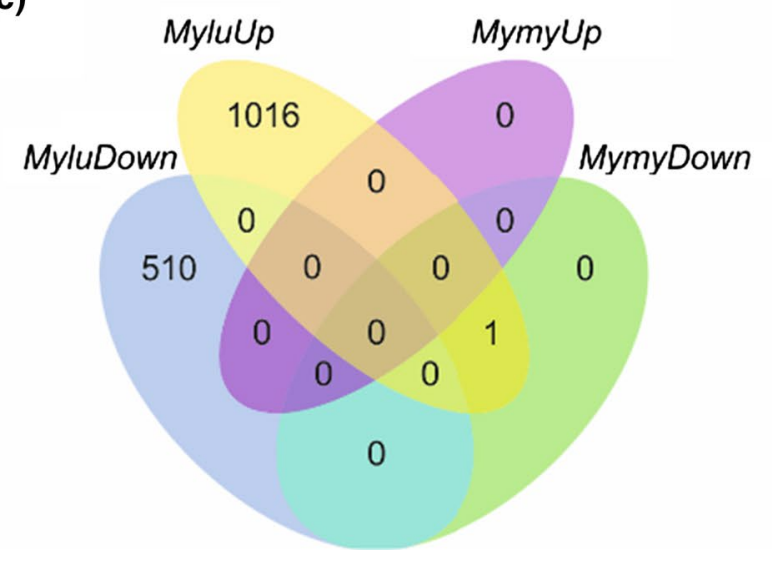

activation involved in immune response (GO:0,002,366, adjusted $\mathrm{p}=2.95 \times 10^{-5}$ ), leukocyte migration (GO:0,050,900, adjusted $p=3.63 \times 10^{-5}$ ), and inflammatory response (GO:0,006,954, adjusted $p=8.06 \times 10^{-4}$ ). All of the genes differentially expressed in these categories due to local 
Table 1 Select immune genes differentially expressed in UV-positive tissue with P. destructans in M. myotis and M. lucifugus

\begin{tabular}{|c|c|c|c|c|c|c|}
\hline \multirow[t]{2}{*}{ Transcript } & \multirow[t]{2}{*}{ Name } & \multirow[t]{2}{*}{ Description } & \multicolumn{2}{|c|}{ M. lucifugus } & \multicolumn{2}{|c|}{ M. myotis } \\
\hline & & & FC & FDR & $\mathrm{FC}$ & FDR \\
\hline ENSMLUT00000015856 & IL6 & Interleukin 6 & 9.58 & $9.65 \mathrm{e}-26$ & NA & NA \\
\hline ENSMLUT00000011363 & CCL2 & $\mathrm{C}-\mathrm{C}$ motif chemokine 2 & 7.46 & $5.92 \mathrm{e}-25$ & 1.67 & 1 \\
\hline ENSMLUT00000008206 & PTGS2 & Prostaglandin-endoperoxide synthase 2 & 15.89 & $1.87 \mathrm{e}-20$ & 1.27 & 1 \\
\hline ENSMLUT00000008807 & HMOX1 & Heme oxygenase 1 & 4.20 & $9.96 \mathrm{e}-17$ & 1.21 & 1 \\
\hline ENSMLUT00000012289 & ICAM1 & Intercellular adhesion molecule 1 & 4.29 & $3.11 \mathrm{e}-16$ & 1.57 & 1 \\
\hline ENSMLUT00000016420 & THBS1 & Thrombospondin 1 & 6.28 & $1.72 \mathrm{e}-13$ & 1.06 & 1 \\
\hline ENSMLUT00000001355 & MMP25 & Matrix metallopeptidase 25 & 35.75 & $2.39 \mathrm{e}-13$ & 2.19 & 1 \\
\hline ENSMLUT00000004880 & $\mathrm{CXCR} 2$ & $\mathrm{C}-\mathrm{X}-\mathrm{C}$ motif chemokine receptor 2 & 24.25 & $2.53 \mathrm{e}-13$ & 2.60 & 1 \\
\hline ENSMLUT00000015164 & NOD2 & Nucleotide binding oligomerization domain containing 2 & 3.86 & $3.41 \mathrm{e}-13$ & 1.20 & 1 \\
\hline ENSMLUT00000029244 & TNFAIP6 & TNF alpha induced protein 6 & 3.81 & $6.61 \mathrm{e}-13$ & 1.18 & 1 \\
\hline ENSMLUT00000011581 & CLEC4E & C-type lectin domain family 4 member $\mathrm{E}$ & 29.04 & $7.63 \mathrm{e}-12$ & NA & NA \\
\hline ENSMLUT00000000289 & MMP9 & Matrix metallopeptidase 9 & 12.21 & $1.38 \mathrm{e}-10$ & 3.18 & 0.09 \\
\hline ENSMLUT00000002542 & CXCL16 & $\mathrm{C}-\mathrm{X}-\mathrm{C}$ motif chemokine ligand 16 & 2.35 & $1.49 \mathrm{e}-09$ & 1.25 & 1 \\
\hline ENSMLUT00000000473 & ANXA1 & Annexin A1 & 2.87 & $1.55 \mathrm{e}-09$ & 0.96 & 1 \\
\hline ENSMLUT00000008598 & SELE & Selectin E & 4.86 & $2.21 \mathrm{e}-09$ & 0.93 & 1 \\
\hline ENSMLUT00000014922 & SHB & $\mathrm{SH} 2$ domain containing adaptor protein B & 2.06 & $7.73 \mathrm{e}-09$ & 1.13 & 1 \\
\hline ENSMLUT00000012386 & FFAR2 & Free fatty acid receptor 2 & 14.72 & $9.26 \mathrm{e}-09$ & 4.76 & 0.22 \\
\hline ENSMLUT00000003161 & ITGB2 & Integrin subunit beta 2 & 17.88 & $9.69 \mathrm{e}-09$ & 2.71 & 0.54 \\
\hline ENSMLUT00000011719 & NR4A3 & Nuclear receptor subfamily 4 group A member 3 & 2.77 & $1.59 \mathrm{e}-08$ & 1.00 & 1 \\
\hline ENSMLUT00000006594 & RELB & RELB proto-oncogene, NF-kB subunit & 2.14 & $1.73 \mathrm{e}-08$ & 1.18 & 1 \\
\hline ENSMLUT00000002906 & S100A8 & S100 calcium binding protein A8 & 3.76 & $4.98 \mathrm{e}-08$ & 1.29 & 1 \\
\hline ENSMLUT00000003286 & SBNO2 & Strawberry notch homolog 2 & 2.64 & $1.02 \mathrm{e}-07$ & 1.15 & 1 \\
\hline ENSMLUT00000011146 & TRPM2 & Transient receptor potential cation channel subfamily $\mathrm{M}$ member 2 & 14.62 & $1.29 \mathrm{e}-07$ & NA & NA \\
\hline ENSMLUT00000012815 & TLR2 & Toll like receptor 2 & 3.29 & $1.33 \mathrm{e}-07$ & 1.13 & 1 \\
\hline ENSMLUT00000003912 & TLR7 & Toll like receptor 7 & 6.87 & $1.71 \mathrm{e}-07$ & NA & NA \\
\hline ENSMLUT00000007434 & PTPN22 & Protein tyrosine phosphatase, non-receptor type 22 & 10.56 & $1.71 \mathrm{e}-07$ & 1.41 & 1 \\
\hline ENSMLUT00000014401 & LCP1 & Lymphocyte cytosolic protein 1 & 19.03 & $2.19 \mathrm{e}-07$ & 3.03 & 0.43 \\
\hline ENSMLUT00000008567 & SELL & Selectin L & 42.81 & $2.31 \mathrm{e}-07$ & 3.34 & 1 \\
\hline ENSMLUT00000012752 & TLR8 & Toll like receptor 8 & 29.04 & $3.63 \mathrm{e}-07$ & NA & NA \\
\hline ENSMLUT00000003440 & CORO1A & Coronin 1A & 6.77 & $4.03 e-07$ & 1.68 & 1 \\
\hline ENSMLUT00000008354 & ITGAL & Integrin subunit alpha $\mathrm{L}$ & 14.42 & $1.03 \mathrm{e}-06$ & NA & NA \\
\hline ENSMLUT00000031197 & S100A9 & S100 calcium binding protein A9 & 4.38 & $2.01 \mathrm{e}-06$ & 1.25 & 1 \\
\hline ENSMLUT00000000160 & PTAFR & Platelet activating factor receptor & 6.96 & $2.05 \mathrm{e}-06$ & 2.01 & 1 \\
\hline ENSMLUT00000022221 & JAML & Junction adhesion molecule like & 4.06 & $2.22 \mathrm{e}-06$ & 1.16 & 1 \\
\hline ENSMLUT00000001008 & SERPINE1 & Serpin family E member 1 & 3.53 & $2.72 \mathrm{e}-06$ & 1.32 & 1 \\
\hline ENSMLUT00000015767 & THY1 & Thy- 1 cell surface antigen & 3.36 & $6.87 \mathrm{e}-06$ & 1.03 & 1 \\
\hline ENSMLUT00000000245 & TFRC & Transferrin receptor & 2.46 & $1.01 \mathrm{e}-05$ & 0.92 & 1 \\
\hline ENSMLUT00000014583 & FGR & FGR protooncogene Src tyrosine kinase & 8.57 & $1.66 \mathrm{e}-05$ & 1.91 & 1 \\
\hline ENSMLUT00000007409 & TLR4 & Toll like receptor 4 & 3.84 & $2.07 \mathrm{e}-05$ & 1.32 & 1 \\
\hline ENSMLUT00000008843 & IL17C & Interleukin $17 \mathrm{C}$ & 5.39 & $2.10 \mathrm{e}-05$ & NA & NA \\
\hline
\end{tabular}

Ensembl transcript ID and gene name are listed for selected transcripts differentially expressed in M. lucifugus between UV-negative and UVpositive tissue. The fold change (FC) and Benjamini-Hochberg adjusted p value (FDR) calculated by edgeR are shown for each transcript for samples from both M. lucifugus and M. myotis samples. Bold FDR values indicate $\leq 0.05$. NA indicates transcripts that were removed by filtering for low expression level (TPM $<1$ in 5 or more samples) prior to edgeR testing. See Table $\mathrm{S} 1$ for results for all transcripts

infection in $M$. lucifugus showed lower fold-changes due to infection in $M$. myotis and were not differentially expressed in UV-positive tissue in M. myotis (Fig. 3 and Supplemental dataset 1) or correlated with biopsy location in M. lucifugus (Supplemental dataset 4).

In a previous study using the same paired sampling approach in captive bats Field et al. (2018), we found that $M$. 


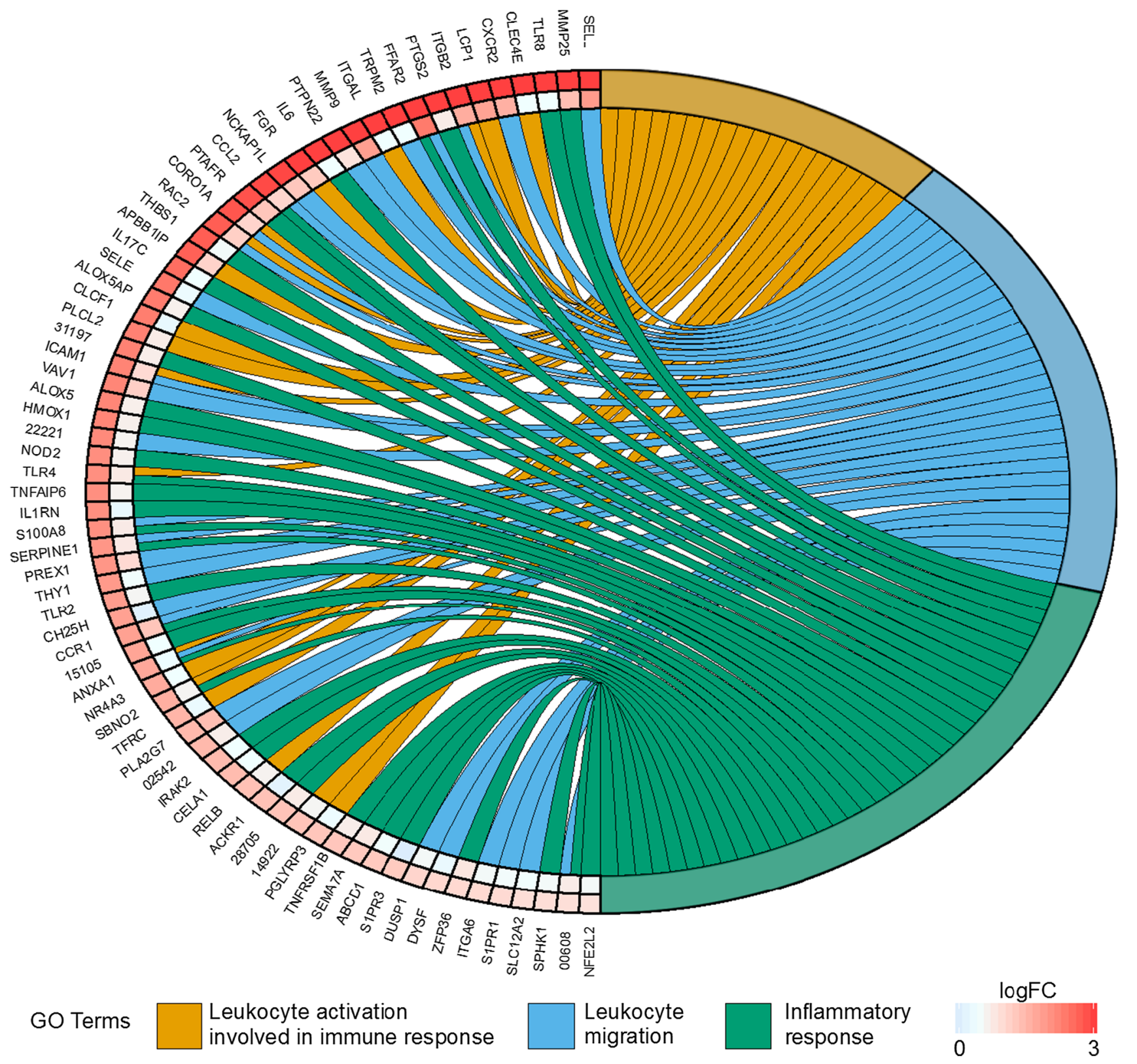

Fig. 3 Chordplot of genes involved in immune responses in $M$. lucifugus identified by gene ontology analysis. Connections from the right side of the figure to the left signify associations between transcripts and selected biological process categories. All transcripts differentially expressed (FDR $<0.05$ by edgeR) are shown that were annotated in the following categories: GO: 0,002,366 (leucocyte acti-

lucifugus from a population of bats from Wisconsin, naïve to $P$. destructans exposure, showed robust local responses to $P$. destructans infection after arousal from torpor. To determine if the local responses to $P$. destructans differ in populations of bats with presumed prior exposure to $P$. destructans infection, we compared the differential expression of transcripts due to infection between the Wisconsin and Pennsylvania populations after correcting for individual variation (and any vation involved in immune response (orange)), GO: 0,050,900 (Leukocyte migration (blue)), and GO: 0,006,954 (Inflammatory response (green)). Expression level changes ( $\log _{2}$ fold change) are shown for the comparison of UV-negative to UV-positive M. lucifugus (outer heatmap) and UV-negative to UV-positive $M$. myotis (inner heatmap) (color figure online)

batch effects). We compared the expression of transcripts in the categories of genes identified from the gene ontology analysis of the current study and found differing patterns of differential expression between the naïve M. lucifugus from Wisconsin, the experienced M. lucifugus from Pennsylvania and the M. myotis from the Czech Republic (Fig. 4). We found that none of the genes in these categories were differentially expressed due to local infection in the $M$. 
Fig. 4 Normalized expression levels of transcripts among M. lucifugus (Wisconsin and Pennsylvania, left to right) and $M$. myotis involved in a leukocyte activation, b leukocyte migration and $\mathbf{c}$ inflammatory response. All transcripts differentially expressed in Pennsylvania $M$. lucifugus samples (FDR $<0.05$ by edgeR) are shown that were annotated in the following categories: a GO:0,002,366 (leucocyte activation involved in immune response (orange)), b GO: 0,050,900 (Leukocyte migration (blue)), and c GO: 0,006,954 (Inflammatory response (green)) (color figure online)

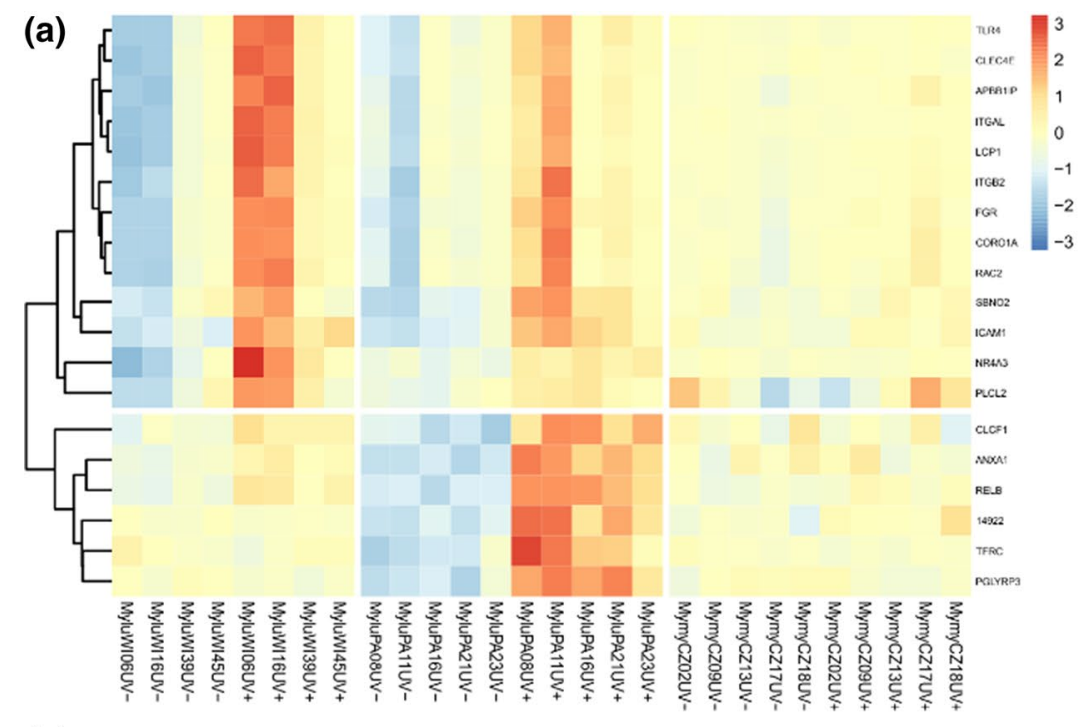

(b)

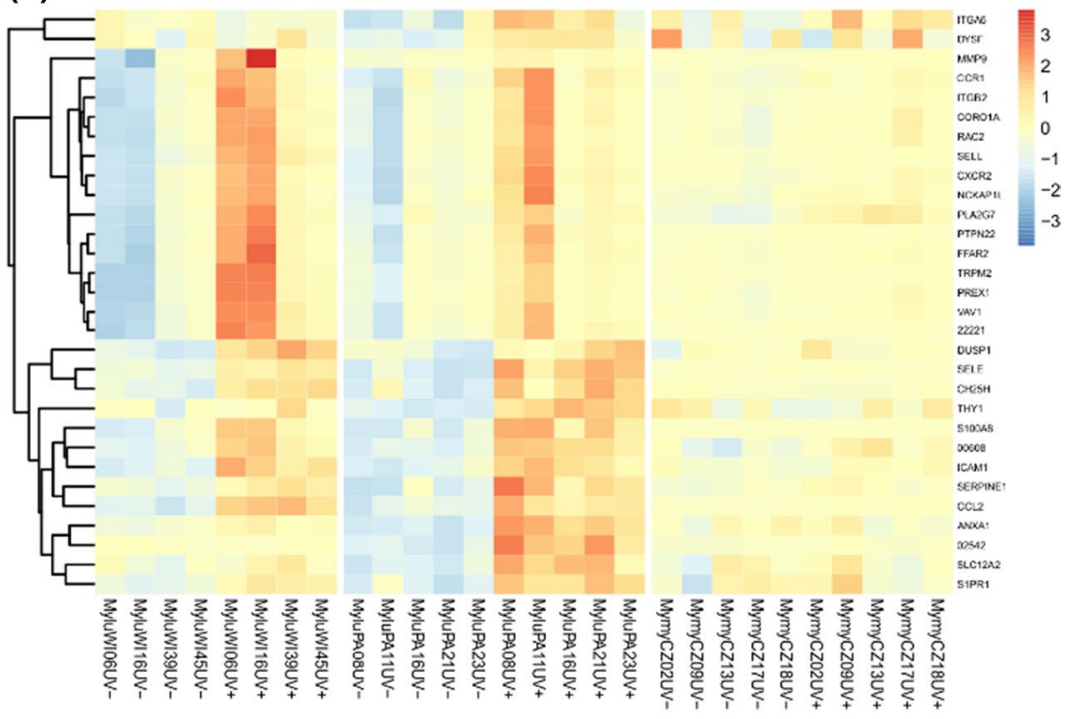

(c)

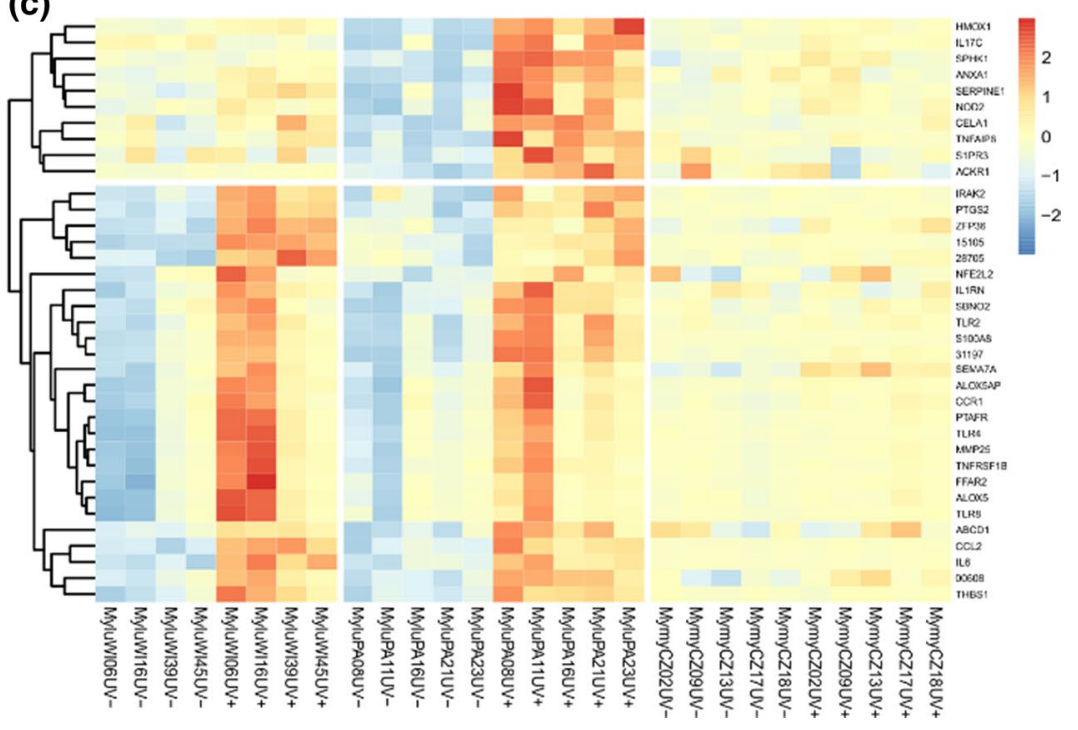


myotis samples. In contrast, some of these genes showed very high levels of upregulation due to local infection in the M. lucifugus from Wisconsin and the pattern of expression levels varied in individual bats in ways that were distinct from the M. lucifugus from Pennsylvania.

\section{Discussion}

Our study demonstrates a potential mechanism of tolerance as a host defense mechanism against pathogens (Boots and Bowers 1999; Miller et al. 2006; Kutzer and Armitage 2016; Soares et al. 2017; Ganeshan et al. 2019). Tolerance is a damage control mechanism that prevents the deleterious effects of pathogens and uncouples immune-driven resistance mechanisms from immunopathology and disease (Soares et al. 2017). In mice and humans, tolerance to malaria has been shown to depend on the anti-inflammatory properties of heme oxygenase-1 (Råberg et al. 2007; Ferreira et al. 2011). Immune responses to fungi are tuned to balance tolerance to environmental and commensal fungi and protective responses to pathogens (Iliev and Underhill 2013), and excessive tissue damage is prevented through modulation of interleukin-17 signalling (Song et al. 2015). Our results support an additional mechanism of tolerance that plays a role in the survival of WNS in M. myotis, dampening or delaying a damaging immune response until resources are available, after emergence from hibernation.

Although hosts may cope with infections through resistance responses and tolerance, only the latter is predicted to be favored by natural selection in the long-term and become eventually fixed (Roy and Kirchner 2000). Our data support this prediction. Populations of M. lucifugus, which have newly encountered $P$. destructans, suffer high mortality from infection and we show that $M$. lucifugus, even in so-called survivor populations individuals exhibit clear transcription profiles of immune gene expression. By contrast, $M$. myotis, which has coexisted with the pathogen for millennia, are commonly infected by the pathogen but exhibit no immune response to infection despite associated pathology. The study emphasizes the advantage of studying this wildlife disease in natural conditions instead of in laboratory settings, where the hosts are not prone to infection.

Our paired sampling protocol enabled a transcriptomewide comparison of during-arousal, local responses of two bat species naturally infected with the fungal pathogen, $P$. destructans. The Palearctic $M$. myotis with a lengthy coexistence with $P$. destructans showed no significant transcriptional response to infection (one downregulated gene between comparisons). The relationship between the $M$. myotis host and the fungus may have evolved into a commensal relationship that allows the host to tolerate the infection without disrupting hibernation. The Nearctic remnant
M. lucifugus population studied here, only subjected to the pathogen since c. 2009, showed abundant transcriptional responses (1526 significantly upregulated or downregulated transcripts) that include an upregulated immune response to the pathogen, presumably an attempt at resistance. In the light of catastrophic population declines in affected Nearctic species, this attempted resistance response could contribute to the increased arousals from torpor and emaciation associated with WNS pathology (Reeder et al. 2012; Meteyer et al. 2012; Warnecke et al. 2013; Lilley et al. 2017). Conversely, $M$. myotis appears to tolerate $P$. destructans infection during periodic arousals from torpor. Although other factors are also likely at play, the absence of a response in $M$. myotis suggests that this species could have adapted to endemic $P$. destructans exposure by tolerating infection, at least during periodic arousals, allowing for valuable energy reserves to be preserved during hibernation. This reduced investment in immune responses during hibernation is consistent with the energetic trade-offs that have been observed during daily heterothermy in mice (Ganeshan et al. 2019). Hibernation represents an extreme state of hypometabolism and the lack of local response to infection seen in M. myotis may represent a favorable energetic trade-off to conserve energy until emergence when a robust immune response is within the energy budget (Ganeshan et al. 2019).

We did not observe a response in $M$. myotis that involved the downregulation of inflammatory genes nor the upregulation of anti-inflammatory or tissue repair genes. Genes involved in modulation of the immune response, tissue regeneration, and wound healing show signals of positive selection in M. myotis (Harazim et al. 2018). It is possible that these classes of genes play an important role in WNS tolerance after emergence from hibernation (Meteyer et al. 2012; Meierhofer et al. 2018) and were not evident in our analysis within the first 60-120 min post-arousal.

Our sampling protocol was not designed to detect systemic changes in host gene expression Field et al. (2018), so we cannot rule out that $M$. myotis do respond to mycosis by altering gene expression in both UV-positive and UVnegative tissues or in other organs. However, given the complete absence of a response at the local level, we consider this unlikely. Although the transcriptional activity of the fungus was comparable between the species within the lesions themselves, M. myotis had fewer total lesions than $M$. lucifugus, suggesting the growth of $P$. destructans in $M$. myotis could be controlled by other factors not associated with transcriptional host responses during arousals. These factors may include abiotic environmental conditions (Johnson et al. 2014), microbial competition (Cornelison et al. 2014; Micalizzi et al. 2017), and the antifungal properties of epidermal fatty acid esters (Frank et al. 2018).

The two main groups of enriched genes in the UV-positive $M$. lucifugus samples were associated with muscle 
cells and immune responses. The muscle development and function genes correlate with sampling location and do not appear to be associated with $P$. destructans infection; the plagiopatagium has muscles, whereas the chiropatagium does not. The immune response pathways that are upregulated include immune cell activation, migration, and inflammatory pathways. These results are very similar to those seen in responses to $P$. destructans in $M$. lucifugus that had not encountered the fungus previously Field et al. $(2015,2018)$. Genes with putative immune function, such as $I L 6, C C L 2$, PTGS2, ICAM1, MMP25, CLEC4E, FFAR2, and SELL have also been found to be upregulated at both the local Field et al. (2018) and systemic levels (Field et al. 2015) during WNS. The local response in M. lucifugus appears to be highly inflammatory and includes pro-inflammatory cytokines, chemokines, and damage-associated molecular pattern recognition molecules. There are 11 putative $\mathrm{S} 100$ protein transcripts significantly upregulated in M. lucifugus (Supplemental dataset 1) and none of these transcripts were significantly upregulated in the M. myotis samples. These S100 proteins are part of an inflammatory response to the pathogen, but one that is pathological because of the magnitude and/or the timing of the response during the hibernation period.

Although the bats sampled from a remnant population in Pennsylvania, in which the population of bats have survived with $P$. destructans exposure for almost 10 years, share many differentially expressed genes with the naive population in Wisconsin, there are some interesting differences. Some genes involved in immune responses show greater local responses to $P$. destructans infection, while others show attenuated responses (Fig. 4). This may indicate that a different type of response has already been selected for in bats in the Pennsylvania populations (Johnson et al. 2016; Cheng et al. 2019), which also showed greater variation in responses between individuals. Alternatively, selection for phenotypic plasticity in their response may allow individual bats to persist over time in the face of WNS.

It appears that remnant populations of $M$. lucifugus in North America are responding to the mycosis caused by $P$. destructans differently to naïve populations, which are coming into contact with the pathogen for the first time. However, even though the response may have shifted in the remnant bats, it is still very different to the complete lack of response in the Palearctic M. myotis. Whether the shift in response to mycosis in the remnant populations contributes to survival needs to be further assessed quantitatively in conjunction with other factors that have been found to contribute to survival (Johnson et al. 2014; Frick et al. 2017; Micalizzi et al. 2017, p. 2; Frank et al. 2018; Cheng et al. 2019). However, with small host population sizes affected by an opportunistic environmental pathogen, the possibility of stochastic effects on these remnant populations should be of great concern as climate change continues to escalate (Gallana et al. 2013; European Environment Agency 2016) and the biomass of the diet these bats depend on, insects (Hallmann et al. 2017) has begun to dwindle.

The results from this study support a model that Nearctic bats when first encountering the novel $P$. destructans pathogen, exhibit a pathological response. There are several important implications of this model. First, the response to $P$. destructans infection should attenuate over time as the result of selective pressure or phenotypic plasticity. We may be seeing some initial evidence of this adaptation in North America [Fig. 4 (Lilley et al. 2016; Langwig et al. 2017; Cheng et al. 2019)]. Second, WNS intervention strategies designed to heighten the host response to $P$. destructans infection may lead to increased pathology. This may explain the difficulty in designing an effective vaccine or other treatment methods (Johnson et al. 2014; Lilley et al. 2017; Rocke et al. 2019), and suggests that caution should be taken in testing such an approach. Third, our results point to the need for further study of the gene expression responses in additional populations and species of Nearctic and Palearctic bats. If it is true that species, populations, and individuals that tolerate infection are able to better cope with WNS, then further studies can help predict the fate of bats in the face of this, and other, anthropogenic challenges.

Acknowledgements Open access funding provided by University of Helsinki including Helsinki University Central Hospital. We thank Riley Bernard for proofreading the document and Mike Scafini (PAGC) for assistance in the field.

Author contribution statement TML, KAF, DMR and SP conceived and designed the study. JSJ, GGT, TB and EB procured the samples. TML and JMP performed lab work. performed the experiments. KAF analyzed the data. TML, ASB, JMP and KAF wrote the manuscript; other authors provided editorial advice.

Funding This work was funded by H2020 Marie SkłodowskaCurie Actions to [706196. Thomas M. Lilley]. Masaryk University MUNI/A/1436/2018. Czech Science Foundation No. 17-20286S.

Data accessibility Sequence data is available through NCBI via SRA accession PRJNA564421.

Open Access This article is distributed under the terms of the Creative Commons Attribution 4.0 International License (http://creativeco mmons.org/licenses/by/4.0/), which permits unrestricted use, distribution, and reproduction in any medium, provided you give appropriate credit to the original author(s) and the source, provide a link to the Creative Commons license, and indicate if changes were made.

\section{References}

Abbott RC, Saindon L, Falendysz EA et al (2019) Rabies outbreak in captive big brown bats (Eptesicus fuscus) used in a 
white-nose syndrome vaccine trial. J Wildl Dis. https://doi. org/10.7589/2018-10-258

Bandouchova H, Bartonicka T, Berkova H et al (2015) Pseudogymnoascus destructans: evidence of virulent skin invasion for bats under natural conditions, Europe. Transbound Emerg Dis 62:1-5. https://doi.org/10.1111/tbed.12282

Bandouchova H, Bartonička T, Berkova H et al (2018) Alterations in the health of hibernating bats under pathogen pressure. Sci Rep 8:6067. https://doi.org/10.1038/s41598-018-24461-5

Bernard RF, Foster JT, Willcox EV et al (2015) Molecular detection of the causative agent of white-nose syndrome on Rafinesque's bigeared bats (Corynorhinus rafinesquii) and two species of migratory bats in the southeastern USA. J Wildl Dis 51:519-522. https ://doi.org/10.7589/2014-08-202

Blehert DS, Hicks AC, Behr M et al (2009) Bat white-nose syndrome: an emerging fungal pathogen? Science 323:227. https://doi. org/10.1126/science. 1163874

Boots M, Bowers RG (1999) Three mechanisms of host resistance to microparasites - avoidance, recovery and tolerance - show different evolutionary dynamics. J Theor Biol 201:13-23. https://doi. org/10.1006/jtbi.1999.1009

Busby MA, Stewart C, Miller CA et al (2013) Scotty: a web tool for designing RNA-Seq experiments to measure differential gene expression. Bioinformatics 29:656-657. https://doi.org/10.1093/ bioinformatics/btt015

Campana M, Kurata N, Foster JT et al (2017) White-nose syndrome fungus in a 1918 bat specimen from France. Emerg Infect Dis J 23:1-1. https://doi.org/10.3201/eid2309.170875

Cheng TL, Gerson A, Moore MS et al (2019) Higher fat stores contribute to persistence of little brown bat populations with white-nose syndrome. J Anim Ecol. https://doi.org/10.1111/1365-2656.12954

Cornelison CT, Gabriel KT, Barlament C, Crow SA (2014) Inhibition of Pseudogymnoascus destructans growth from conidia and mycelial extension by bacterially produced volatile organic compounds. Mycopathologia 177:1-10. https://doi.org/10.1007/s1104 6-013-9716-2

Daszak P, Cunningham AA, Hyatt AD (2000) Emerging infectious diseases of wildlife-threats to biodiversity and human health. Science 287:443-449. https://doi.org/10.1126/science.287.5452.443

Davy CM, Donaldson ME, Willis CKR et al (2017) The other white-nose syndrome transcriptome: tolerant and susceptible hosts respond differently to the pathogen Pseudogymnoascus destructans. Ecol Evol. https://doi.org/10.1002/ece3.3234

Dobin A, Davis CA, Schlesinger F et al (2013) STAR: ultrafast universal RNA-seq aligner. Bioinformatics 29:15-21. https://doi. org/10.1093/bioinformatics/bts635

Dobony CA, Johnson JB (2018) Observed resiliency of little brown myotis to long-term white-nose syndrome exposure. J Fish Wildl Manag 9:168-179. https://doi.org/10.3996/102017-JFWM-080

Drees KP, Palmer JM, Sebra R et al (2016) Use of multiple sequencing technologies to produce a high-quality genome of the fungus Pseudogymnoascus destructans, the causative agent of bat whitenose syndrome. Genome Announc. https://doi.org/10.1128/genom eA.00445-16

Eskew EA, Todd BD (2013) Parallels in amphibian and bat declines from pathogenic fungi. Emerg Infect Dis 19:379-385. https://doi. org/10.3201/eid1093.120707

European Environment Agency (2016) Climate change, impacts and vulnerability in Europe 2016. Publications Office of the EuropeanUnion, Luxembourg. https://www.eea.europa.eu/publications/ climate-change-impacts-and-vulnerability-2016

Ferreira A, Marguti I, Bechmann I et al (2011) Sickle hemoglobin confers tolerance to plasmodium infection. Cell 145:398-409. https ://doi.org/10.1016/j.cell.2011.03.049
Field KA, Johnson J, Lilley T et al (2015) The white-nose syndrome transcriptome: activation of anti-fungal host responses in wing tissue of hibernating bats. PLoS Pathog 11:e1005168

Field KA et al (2018a) Quantification of pathogen levels is necessary to compare responses to pathogen exposure: comment on Davy et al. "The other white-nose syndrome transcriptome". Ecol Evol 8:5235-5237. https://doi.org/10.1002/ece3.4034

Field KA, Sewall BJ, Prokkola JM et al (2018b) Effect of torpor on host transcriptomic responses to a fungal pathogen in hibernating bats. Mol Ecol. https://doi.org/10.1111/mec.14827

Frank CL, Sitler-Elbel KG, Hudson AJ, Ingala MR (2018) The antifungal properties of epidermal fatty acid esters: insights from whitenose syndrome (WNS) in bats. Molecules 23:1986. https://doi. org/10.3390/molecules23081986

Frick WF, Pollock JF, Hicks AC et al (2010) An emerging disease causes regional population collapse of a common North American bat species. Science 329:679-682. https://doi.org/10.1126/science.1188594

Frick WF, Cheng TL, Langwig KE et al (2017) Pathogen dynamics during invasion and establishment of white-nose syndrome explain mechanisms of host persistence. Ecology 98:624-631. https://doi.org/10.1002/ecy.1706

Gallana M, Ryser-Degiorgis M-P, Wahli T, Segner H (2013) Climate change and infectious diseases of wildlife: altered interactions between pathogens, vectors and hosts. Curr Zool 59:427-437. https://doi.org/10.1093/czoolo/59.3.427

Ganeshan K, Nikkanen J, Man K et al (2019) Energetic trade-offs and hypometabolic states promote disease tolerance. Cell. https ://doi.org/10.1016/j.cell.2019.01.050

Hallmann CA, Sorg M, Jongejans E et al (2017) More than 75 percent decline over 27 years in total flying insect biomass in protected areas. PLoS One 12:e0185809. https://doi.org/10.1371/ journal.pone.0185809

Harazim M, Horáček I, Jakešová L et al (2018) Natural selection in bats with historical exposure to white-nose syndrome. BMC Zool 3:8. https://doi.org/10.1186/s40850-018-0035-4

Iliev ID, Underhill DM (2013) Striking a balance: fungal commensalism versus pathogenesis. Curr Opin Microbiol 16:366-373. https://doi.org/10.1016/j.mib.2013.05.004

Johnson WE, Li C, Rabinovic A (2007) Adjusting batch effects in microarray expression data using empirical Bayes methods. Biostatistics 8:118-127. https://doi.org/10.1093/biostatistics/ kxj037

Johnson JS, Reeder DM, McMichael JW III et al (2014) Host, pathogen, and environmental characteristics predict white-nose syndrome mortality in captive little brown myotis (Myotis lucifugus). PLoS One 9:e112502. https://doi.org/10.1371/journal.pone.01125 02

Johnson JS, Reeder DM, Lilley TM et al (2015) Antibodies to Pseudogymnoascus destructans are not sufficient for protection against white-nose syndrome. Ecol Evol. https://doi.org/10.1002/ ece3.1502

Johnson JS, Scafini M, Sewall BJ, Turner GG (2016) Hibernating bat species in Pennsylvania use colder winter habitats following the arrival of white-nose syndrome. In: Butchkoski CM, Reeder DM, Turner GG, Whidden HP (eds) Conservation and Ecology of Pennsylvania's Bats. The Pennsylvania Academy of Sciences, Bradford, pp 181-199

Joshi N, Fass J (2011) Sickle: A sliding-window, adaptive, qualitybased trimming tool for FastQ files (Version 1.33) [Software]. https://github.com/najoshi/sickle. Accessed 04 Nov 2018

Kutzer MAM, Armitage SAO (2016) Maximising fitness in the face of parasites: a review of host tolerance. Zool (Jena) 119:281-289. https://doi.org/10.1016/j.zool.2016.05.011

Langwig KE, Hoyt JR, Parise KL et al (2017) Resistance in persisting bat populations after white-nose syndrome invasion. Phil Trans R Soc B 372:20160044. https://doi.org/10.1098/rstb.2016.0044 
Leopardi S, Blake D, Puechmaille SJ (2015) White-nose syndrome fungus introduced from Europe to North America. Curr Biol 25:R217-R219. https://doi.org/10.1016/j.cub.2015.01.047

Li B, Dewey CN (2011) RSEM: accurate transcript quantification from RNA-Seq data with or without a reference genome. BMC Bioinform 12:323. https://doi.org/10.1186/1471-2105-12-323

Lilley TM, Johnson JS, Ruokolainen L et al (2016) White-nose syndrome survivors do not exhibit frequent arousals associated with Pseudogymnoascus destructans infection. Front Zool 13:12. https ://doi.org/10.1186/s12983-016-0143-3

Lilley TM, Prokkola JM, Johnson JS et al (2017) Immune responses in hibernating little brown myotis (Myotis lucifugus) with white-nose syndrome. Proc R Soc B 284:20162232. https://doi.org/10.1098/ rspb.2016.2232

Lilley T, Anttila J, Ruokolainen L (2018) Landscape structure and ecology influence the spread of a bat fungal disease. Funct Ecol. https://doi.org/10.1111/1365-2435.13183

Love MI, Huber W, Anders S (2014) Moderated estimation of fold change and dispersion for RNA-seq data with DESeq2. Genome Biol 15:550. https://doi.org/10.1186/s13059-014-0550-8

Martin M (2011) Cutadapt removes adapter sequences from highthroughput sequencing reads. EMBnet J 17:10. https://doi. org/10.14806/ej.17.1.200

Martinkova N, Backor P, Bartonicka T et al (2010) Increasing incidence of Geomyces destructans fungus in bats from the Czech Republic and Slovakia. PLoS One 5:e13853. https://doi.org/10.1371/journ al.pone. 0013853

Medzhitov R, Schneider DS, Soares MP (2012) Disease tolerance as a defense strategy. Science 335:936-941. https://doi.org/10.1126/ science. 1214935

Meierhofer MB, Johnson JS, Field KA et al (2018) Bats recovering from white-nose syndrome elevate metabolic rate during wing healing in spring. J Wildl Dis 54:480-490. https://doi. org/10.7589/2017-08-195

Meteyer CU, Buckles EL, Blehert DS et al (2009) Histopathologic criteria to confirm white-nose syndrome in bats. J Vet Diagn Invest 21:411-414

Meteyer CU, Barber D, Mandl JN (2012) Pathology in euthermic bats with white nose syndrome suggests a natural manifestation of immune reconstitution inflammatory syndrome. Virulence 3:583588. https://doi.org/10.4161/viru.22330

Micalizzi EW, Mack JN, White GP et al (2017) Microbial inhibitors of the fungus Pseudogymnoascus destructans, the causal agent of white-nose syndrome in bats. PLoS One 12:e0179770. https://doi. org/10.1371/journal.pone.0179770

Miller MR, White A, Boots M (2006) The evolution of parasites in response to tolerance in their hosts: the good, the bad, and apparent commensalism. Evolution 60:945-956. https://doi. org/10.1111/j.0014-3820.2006.tb01173.x

Moore MS, Field KA, Behr MJ et al (2018) Energy conserving thermoregulatory patterns and lower disease severity in a bat resistant to the impacts of white-nose syndrome. J Comp Physiol B 188:163-176. https://doi.org/10.1007/s00360-017-1109-2

Pikula J, Bandouchova H, Novotny L et al (2012) Histopathology confirms white-nose syndrome in bats in Europe. J Wildl Dis 48:207-211

Pikula J, Amelon SK, Bandouchova H et al (2017) White-nose syndrome pathology grading in Nearctic and Palearctic bats. PLoS One 12:e180435. https://doi.org/10.1371/journal.pone.0180435

Puechmaille SJ, Wibbelt G, Korn V et al (2011) Pan-European distribution of white-nose syndrome fungus (Geomyces destructans) not associated with mass mortality. PLoS One 6:e19167. https://doi. org/10.1371/journal.pone.0019167

Råberg L, Sim D, Read AF (2007) Disentangling genetic variation for resistance and tolerance to infectious diseases in animals. Science 318:812-814. https://doi.org/10.1126/science.1148526
Råberg L, Graham AL, Read AF (2009) Decomposing health: tolerance and resistance to parasites in animals. Philos Trans R Soc Lond B Biol Sci 364:37-49. https://doi.org/10.1098/rstb.2008.0184

Reeder DM, Frank CL, Turner GG et al (2012) Frequent arousal from hibernation linked to severity of infection and mortality in bats with white-nose syndrome. PLoS One. https://doi.org/10.1371/ journal.pone.0038920

Reimand J, Arak T, Adler P et al (2016) g:profiler-a web server for functional interpretation of gene lists (2016 update). Nucleic Acids Res 44:W83-W89. https://doi.org/10.1093/nar/gkw199

Robinson MD, McCarthy DJ, Smyth GK (2010) edgeR: a Bioconductor package for differential expression analysis of digital gene expression data. Bioinformatics 26:139-140. https://doi.org/10.1093/ bioinformatics/btp616

Rocke TE, Kingstad-Bakke B, Wüthrich M et al (2019) Virally-vectored vaccine candidates against white-nose syndrome induce antifungal immune response in little brown bats (Myotis lucifugus). Sci Rep 9:6788. https://doi.org/10.1038/s41598-019-43210-w

Roy BA, Kirchner JW (2000) Evolutionary dynamics of pathogen resistance and tolerance. Evolution 54:51-63. https://doi. org/10.1111/j.0014-3820.2000.tb00007.x

Ruedi M, Stadelmann B, Gager Y et al (2013) Molecular phylogenetic reconstructions identify East Asia as the cradle for the evolution of the cosmopolitan genus Myotis (Mammalia, Chiroptera). Mol Phylogenetics Evol 69:437-449. https://doi.org/10.1016/j.ympev .2013.08.011

Scholthof K-BG (2007) The disease triangle: pathogens, the environment and society. Nat Rev Microbiol 5:152-156. https://doi. org/10.1038/nrmicro1596

Soares MP, Teixeira L, Moita LF (2017) Disease tolerance and immunity in host protection against infection. Nat Rev Immunol 17:8396. https://doi.org/10.1038/nri.2016.136

Song X, Dai D, He X et al (2015) Growth factor FGF2 cooperates with interleukin-17 to repair intestinal epithelial damage. Immunity 43:488-501. https://doi.org/10.1016/j.immuni.2015.06.024

Su S, Law CW, Ah-Cann C et al (2017) Glimma: interactive graphics for gene expression analysis. Bioinformatics 33:2050-2052. https ://doi.org/10.1093/bioinformatics/btx094

Supek F, Bošnjak M, Škunca N, Šmuc T (2011) REVIGO summarizes and visualizes long lists of gene ontology terms. PLoS One 6:e21800. https://doi.org/10.1371/journal.pone.0021800

Tompkins DM, Carver S, Jones ME et al (2015) Emerging infectious diseases of wildlife: a critical perspective. Trends Parasitol 31:149-159. https://doi.org/10.1016/j.pt.2015.01.007

Turner GG, Meteyer CU, Barton H et al (2014) Nonlethal screening of bat-wing skin with the use of ultraviolet fluorescence to detect lesions indicative of white-nose syndrome. J Wildl Dis 50:566573. https://doi.org/10.7589/2014-03-058

Van der Meij T, Van Strien AJ, Haysom KA et al (2015) Return of the bats? A prototype indicator of trends in European bat populations in underground hibernacula. Mamm Biol 80:170-177. https://doi. org/10.1016/j.mambio.2014.09.004

Varet H, Brillet-Guéguen L, Coppée J-Y, Dillies M-A (2016) SARTools: a DESeq2- and EdgeR-based R pipeline for comprehensive differential analysis of RNA-Seq data. PLoS One. https://doi. org/10.1371/journal.pone.0157022

Verant ML, Meteyer CU, Speakman JR et al (2014) White-nose syndrome initiates a cascade of physiologic disturbances in the hibernating bat host. BMC Physiol 14:10. https://doi.org/10.1186/ s12899-014-0010-4

Warnecke L, Turner JM, Bollinger TK et al (2012) Inoculation of bats with European Geomyces destructans supports the novel pathogen hypothesis for the origin of white-nose syndrome. Proc Natl Acad Sci USA 109:6999-7003. https://doi.org/10.1073/pnas.12003 74109 
Warnecke L, Turner JM, Bollinger TK et al (2013) Pathophysiology of white-nose syndrome in bats: a mechanistic model linking wing damage to mortality. Biol Lett 9:20130177. https://doi. org/10.1098/rsbl.2013.0177

Wibbelt G, Kurth A, Hellmann D et al (2010) White-nose syndrome fungus (Geomyces destructans) in Bats, Europe. Emerg Infect Dis 16:1237-1243. https://doi.org/10.3201/eid1608.100002

Yates A, Akanni W, Amode MR et al (2015) Ensembl 2016. Nucl Acids Res. https://doi.org/10.1093/nar/gkv1157
Zukal J, Bandouchova H, Bartonicka T et al (2014) White-nose syndrome fungus: a generalist pathogen of hibernating bats. PLoS One 9:e97224. https://doi.org/10.1371/journal.pone.0097224

Zukal J, Bandouchova H, Brichta J et al (2016) White-nose syndrome without borders: Pseudogymnoascus destructans infection tolerated in Europe and Palearctic Asia but not in North America. Sci Rep 6:19829. https://doi.org/10.1038/srep19829 